\title{
Influence of the Tungsten Content on Surface Properties of Electroless Ni-W-P Coatings
}

\author{
Mara Cristina Lopes de Oliveira ${ }^{a}$, Olandir Vercino Correa ${ }^{b}$, Bardia Ettc, Isaac Jamil Sayeg ${ }^{d}$, Nelson \\ Batista de Lima ${ }^{b}$, Renato Altobelli Antunes ${ }^{a *}$ \\ ${ }^{a}$ Centro de Engenharia, Modelagem e Ciências Sociais Aplicadas (CECS), Universidade Federal do \\ ABC (UFABC), 09210-580, Santo André, SP, Brazil \\ ${ }^{b}$ Instituto de Pesquisas Energéticas e Nucleares, IPEN/CNEN-SP, Av. Prof. Lineu Prestes, 2242, Cidade \\ Universitária, 05508-900, São Paulo, SP, Brazil \\ ${ }^{c}$ Electrocell. Ind. Com. de Equipamentos Elétricos LTDA, CIETEC, Av. Prof. Lineu Prestes, 2242, \\ Cidade Universitária, 05508-900, São Paulo, SP, Brazil \\ ${ }^{d}$ Instituto de Geociências, Universidade de São Paulo, Rua do Lago, 562, 05508-080, \\ São Paulo, SP, Brazil
}

Received: June 08, 2017; Revised: September 11, 2017; Accepted: October 11, 2017

\begin{abstract}
Ternary Ni-W-P films were produced by electroless deposition using baths with different tungsten concentrations. After deposition, the coated surfaces were annealed at $400^{\circ} \mathrm{C}$ for $1 \mathrm{~h}$. Surface morphology and film composition in the as-plated condition were assessed by SEM and EDS analyses, respectively. The crystalline phases after annealing were investigated by X-ray diffraction (XRD). Nanoindentation tests were performed to assess the mechanical properties of the deposited films. Surface roughness was determined by confocal laser scanning microscopy (CLSM). Friction coefficient was evaluated by reciprocating were tests in a nanotribometer. The corrosion behavior was evaluated by potentiodynamic polarization curves. The results showed that the surface morphology, crystallization behavior and corrosion resistance were affected by the tungsten content in the film. The best corrosion performance was obtained for the ternary films after annealing. Hardness, surface roughness and friction coefficient were dependent of the tungsten concentration in the film.
\end{abstract}

Keywords: $\mathrm{Ni}$-W-P films, electroless deposition, tungsten content, corrosion.

\section{Introduction}

Electroless deposition of Ni-P alloys is traditionally employed to produce films with good adhesion to metallic substrates even with complex geometries, improving both wear and corrosion resistances of the coated surface ${ }^{1,2}$. Engineering applications are, therefore, well-established in several areas such as automotive, textile, chemistry and aeronautics industries ${ }^{3}$. Metallic rebars used as reinforcements of cementitious materials can be protected against chlorideinduced corrosion by Ni-P films ${ }^{4}$. Furthermore, components for the petrochemical industry are frequently protected by electroless Ni-P plating such as valves, risers, pumps and pipes $^{5,6}$. Corrosion resistance is a major concern in all these applications.

The overall performance of binary Ni-P alloys can be enhanced by adding a third element to the deposition bath, thus obtaining ternary coatings. In this context, co-deposition of several elements such as copper, cobalt, tin and cerium has been carried out to modify the original properties of regular Ni-P coatings ${ }^{7-10}$. Properties such as thermal stability, corrosion resistance, electronic conductivity and wear resistance can be improved by properly controlling bath conditions and composition $^{11,12}$.

*e-mail: renato.antunes@ufabc.edu.br
Tungsten plays a central role in this scenario. Tungsten co-deposition in Ni-P matrix has been tested by different authors with the aim at obtaining improved surface properties, especially regarding corrosion and wear characteristics, consolidating and expanding the industrial applications of Ni-P alloys. Palaniappa and Seshadri ${ }^{13}$ showed that tungsten addition enhanced the wear resistance of electroless Ni-P coatings due to solid solution strengthening of the nickel matrix with the incorporation of tungsten. Furthermore, tungsten addition reduces the phosphorus content of the film and modifies its crystalline structure ${ }^{14}$. As a result, the corrosion behavior of Ni-W-P coatings depends on the tungsten content incorporated into the film. There are reports indicating that the corrosion resistance scales with the tungsten content in the film ${ }^{15,16}$. Notwithstanding, there is no consensus in the literature, and conflicting results can be found. Balaraju et al. ${ }^{17}$, for instance, observed that the corrosion resistance of electroless Ni-P films was not improved by tungsten addition. Different responses can arise from interactions between coating morphology, crystalline structure and composition. Yet, it is a common practice to subject the coated substrates to annealing treatments in order to promote the formation of specific crystalline phases that impart high hardness and wear resistance to the films in comparison with the as-deposited condition ${ }^{18}$. The hardness 
increase of binary and ternary electroless nickel coatings that occurs at an annealing temperature of $400^{\circ} \mathrm{C}$ is associated with the precipitation of $\mathrm{Ni}_{3} \mathrm{P}$ crystallites ${ }^{19}$.

The conflicting results reported in the literature regarding the effect of tungsten concentration on the corrosion behavior of electroless Ni-W-P films have motivated the present investigation. Thus, the aim of the present work was to study the effect of tungsten concentration on the corrosion resistance of electroless Ni-P films. After deposition, the films were subjected to an annealing treatment at $400^{\circ} \mathrm{C}$ for $1 \mathrm{~h}$. Next, the annealed films were characterized with regard to their crystalline structure, surface morphology, roughness, hardness, friction and electrochemical behavior.

\section{Experimental}

\subsection{Electroless deposition and heat treatment}

SAE 1020 carbon steel ( 0.20 wt. \% C, 0.35 wt. \% Mn, 0.02 wt. \% P, 0.02 wt. $\% \mathrm{~S}$, Fe balance) specimens with dimensions $3.0 \times 2.0 \times 0.1 \mathrm{~cm}$ were used as substrates for the electroless deposition of Ni-W-P films. Initially, the specimens were degreased in ethyl alcohol, cleaned by immersion in $\mathrm{NaOH}$ 10 wt. $\%$ solution at $50^{\circ} \mathrm{C}$ for 10 minutes and washed in deionized water. Next, surface activation was carried out in sulfuric acid solution (30\%vol) for $30 \mathrm{~s}$, followed by washing in deionized water. After activation, the specimens were immersed in the plating bath.

The plating bath consisted of nickel sulfate $\left(\mathrm{NiSO}_{4} \cdot 6 \mathrm{H}_{2} \mathrm{O}\right)$, sodium citrate $\left(\mathrm{Na}_{3} \mathrm{C}_{6} \mathrm{H}_{5} \mathrm{O}_{7} \cdot 2 \mathrm{H}_{2} \mathrm{O}\right)$, sodium hypohosphite $\left(\mathrm{Na}_{2} \mathrm{H}_{2} \mathrm{PO}_{2} \cdot \mathrm{H}_{2} \mathrm{O}\right)$ and sodium tungstate $\left(\mathrm{Na}_{2} \mathrm{WO}_{4} \cdot 2 \mathrm{H}_{2} \mathrm{O}\right)$. Different compositions were prepared according to Table 1. Bath $\mathrm{pH}$ was controlled during deposition using ammonium hydroxide to maintain an alkaline character with $\mathrm{pH}=9.0$. This is an important step during deposition, since the bath is unstable at acidic $\mathrm{pH}$, forming precipitates. Moreover, the deposition rate is optimized at $\mathrm{pH}=9$ and the charge transfer resistance is $l o w^{20,21}$. Bath temperature was adjusted to $90^{\circ} \mathrm{C}$. Deposition was conducted over $2 \mathrm{~h}$. After deposition, the specimens were removed from the bath, thoroughly washed in deionized water and dried in a warm air stream provided by a simple air blowing gun.

Following plating, the specimens were annealed at $400^{\circ} \mathrm{C}$ in a tubular furnace under air for $1 \mathrm{~h}$. This annealing condition is well-established in the literature for Ni-P films in order to promote the formation of $\mathrm{Ni}_{3} \mathrm{P}$, increasing hardness and achieving the best surface properties ${ }^{16}$. Then, the specimens were furnace-cooled and stored for characterization.

\subsection{Film characterization}

The specimens obtained in baths 1 to 5 (see Table 1) were characterized by X-ray diffraction (XRD) in order to investigate the effect of the tungsten content on the crystalline phases present in the coating layer. The specimens were first subject to an annealing treatment at $400^{\circ} \mathrm{C}$ in tubular furnace under air for $1 \mathrm{~h}$. This temperature was chosen based on literature reports which indicate that the precipitation of $\mathrm{Ni}_{3} \mathrm{P}$ occurs at this this temperature ${ }^{19,22}$. The measurements were made using a Rigaku DMAX-2000 diffractometer with $\mathrm{Cu}-\mathrm{k} \alpha$ radiation in the $2 \theta$ range from $10^{\circ}$ to $70^{\circ}$.

Film morphology was assessed using a scanning electron microscope (LEO 440i) equipped with EDS detector (Oxford, energy dispersive X-ray spectroscopy) to determine the overall chemical composition of the as-deposited coatings. For analysis of film thickness the samples were embedded in cold curing epoxy resin. After complete curing (6 h), the samples were ground using $\mathrm{SiC}$ emery paper (\#600 and \#1200), washed with deionized water and dried. Next, film thickness was determined from analysis of cross-sections of SEM micrographs of the different coatings (Hitachi TM3000 microscope). Coating roughness was determined using confocal laser scanning microscopy (CLSM - Olympus LEXT OLS4100). Profile line-scans were determined for five different regions and the average roughness parameter Ra was calculated.

Nanoindentation tests were performed using a $\mathrm{NHT}^{2}$ Nanoindentation tester (Anton Paar) with a Berkovich indenter. The tests were carriet out at a loading rate of 100 $\mathrm{mN} / \mathrm{min}$, peak load of $50 \mathrm{mN}$ and unloading rate of 100 $\mathrm{mN} / \mathrm{min}$. The peak load was applied for $2 \mathrm{~s}$. The values of hardness and Young's modulus were determined from load versus penetration depth curves using the Oliver \& Pharr method. The results reported here express the average of eight indentations per specimen.

Friction characteristics were assessed by dry sliding reciprocating wear tests using $\mathrm{NTR}^{2}$ Nanotribometer (Anton Paar). The tests were conducted using a $2 \mathrm{~mm}$-diameter chromium steel ball as counter body, applying a normal load of $20 \mathrm{mN}$, frequency of $2 \mathrm{~Hz}$ and wear track amplitude of 1.5

Table 1. Composition of the plating baths.

\begin{tabular}{lccccc}
\hline \multirow{2}{*}{ Component } & \multicolumn{5}{c}{ Concentration $\left(\mathrm{g} . \mathrm{L}^{-1}\right)$} \\
\cline { 2 - 6 } & 1 & 2 & 3 & 4 & 5 \\
\hline $\mathrm{NiSO}_{4} \cdot 6 \mathrm{H}_{2} \mathrm{O}$ & 20 & 20 & 20 & 20 & 20 \\
$\mathrm{Na}_{2} \mathrm{H}_{2} \mathrm{PO}_{2} \cdot \mathrm{H}_{2} \mathrm{O}$ & 20 & 20 & 20 & 20 & 20 \\
$\mathrm{Na}_{3} \mathrm{C}_{6} \mathrm{H}_{5} \mathrm{O}_{7} \cdot 2 \mathrm{H}_{2} \mathrm{O}$ & 35 & 35 & 35 & 35 & 35 \\
$\mathrm{Na}_{2} \mathrm{WO}_{4} \cdot 2 \mathrm{H}_{2} \mathrm{O}$ & ---- & 5 & 10 & 20 & 40 \\
\hline
\end{tabular}


$\mathrm{mm}$. The variation of the coefficient of friction as a function of the sliding distance was registered during 30 minutes.

Electrochemical measurements were performed using a Ivium nStat potentiostat/galvanostat in a conventional three-electrode cell setup with a platinum wire as counterelectrode, $\mathrm{Ag} / \mathrm{AgCl}$ as reference and the coated specimens as working electrodes. Initially, the open circuit potential (OCP) was monitored until a steady state has been reached. Next, potentiodynamic polarization curves were acquired in the potential range from $-300 \mathrm{mV}$ versus the OCP up to $+1,0$ $\mathrm{V}_{\mathrm{Ag} / \mathrm{AgCl}}$ at a sweep rate of $1 \mathrm{mV} \cdot \mathrm{s}^{-1}$. All potentials mentioned in the text are referred to the $\mathrm{Ag} / \mathrm{AgCl}$ system. The electrolyte was a $3.5 \mathrm{wt} . \% \mathrm{NaCl}$ solution at room temperature. The tests were conducted in triplicate.

\section{Results and Discussion}

\subsection{Film structure}

XRD patterns of the films produced in baths 1 to 5 are shown in Fig. 1. The two main peaks at $44.5^{\circ}$ and $51.8^{\circ}$ correspond to reflections of $\mathrm{Ni}(111)$ and $\mathrm{Ni}$ (200) planes. Nickel nanometric crystallites can be formed on Ni-W-P after annealing ${ }^{23}$. The crystalline state of the annealed coatings is confirmed by the presence of several reflections ascribed to $\mathrm{Ni}_{3} \mathrm{P}$ phase. Phase transformations studies of electroless nickel deposits point to the precipitation of $\mathrm{Ni}_{3} \mathrm{P}$ crystallites at temperatures above $350^{\circ} \mathrm{C}$ up to $500^{\circ} \mathrm{C}$, depending on the composition of the plating bath ${ }^{24,25}$. Diffractograms in Fig. 1 unequivocally confirm the presence of $\mathrm{Ni}_{3} \mathrm{P}$ crystallites, independently of the tungsten concentration in the plating bath. One interesting finding is the relative proportion between the $\mathrm{Ni}(111)$ and $\mathrm{Ni}(200)$ reflections. As the tungsten concentration in the plating bath increases from bath 1 to 5 the Ni (200) peak becomes less intense and the Ni (111) increases, indicating that the incorporation of tungsten into the Ni-P matrix modify its crystallization behavior. A similar finding was reported by Balaraju et al. ${ }^{22}$ for Ni-W-P deposits obtained by electroless deposition. When the phosphorus contents decrease and tungsten increases the crystalline character of the film is enhanced and the intensity of the $\mathrm{Ni}$ (111) reflection becomes stronger. This effect seems to have occurred with the films deposited in the present work.

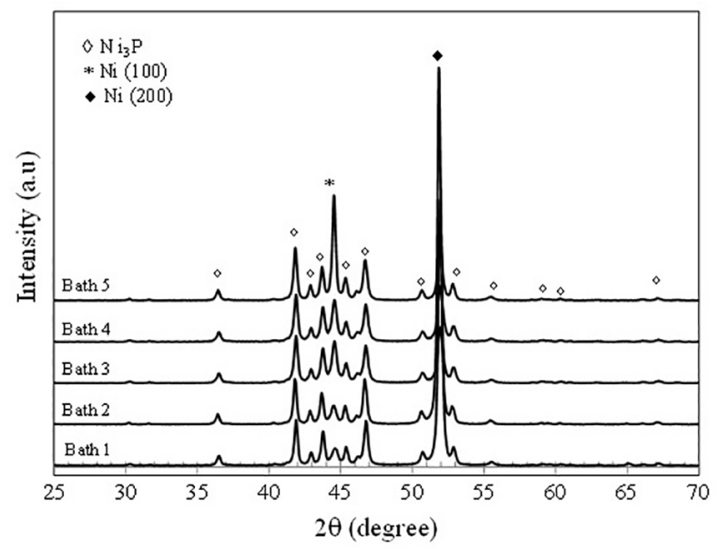

Figure 1. XRD patterns of the coatings obtained in baths with different tungsten concentrations after annealing at $400^{\circ} \mathrm{C}$.

\subsection{Film composition and morphology}

Chemical composition of the films obtained in baths with different tungsten concentrations was determined by EDS analysis. The results are shown in Tab. 2 .

Phosphorus content for the conventional binary Ni-P film obtained from bath 1 is $9.2 \mathrm{wt} \% \%$. Ni-P coatings with phosphorus contents ranging from 6 to $10 \mathrm{wt} . \%$ are considered as medium phosphorus films ${ }^{26}$. This is the case of the films obtained in baths 1, 2, 3 and 4. Only for the films obtained in bath 5 the phosphorus content was lower than $6 \mathrm{wt} . \%$, denoting a low phosphorus coating. As tungsten incorporated into the film, the phosphorus content progressively diminished, as expected. According to Balaraju et al. ${ }^{22}$, the decrease of phosphorus content as tungsten is added to electroless baths used to produce Ni-W-P films would be due to the increase of metals to hypophosphite ratio in the bath. Furthermore, these authors hypothesize that competitive reactions between tungsten and phosphorus compounds can take place or the formation of complex compounds could inhibit the co-deposition of phosphorus during plating. The nickel content was near 90 wt. \% for all the plating baths. The Ni/P, Ni/W and p/W ratios were calculated from the EDS data. The results are displayed in Fig. 2. It is seen that the $\mathrm{Ni} / \mathrm{P}$ increases from baths 1 to 5 due to the reduced phosphorus concentration. The gradual increase of tungsten concentration makes the $\mathrm{Ni} / \mathrm{W}$ and $\mathrm{P} / \mathrm{W}$ ratios decrease from baths 2 to 5 , confirming the results reported by Balaraju et al. ${ }^{22}$.

Table 2. Chemical composition of the coatings obtained in baths with different tungsten concentrations as determined by EDS analysis.

\begin{tabular}{cccc}
\hline \multirow{2}{*}{ Bath } & \multicolumn{3}{c}{ Element (wt.\%) } \\
\cline { 2 - 4 } & $\mathrm{Ni}$ & $\mathrm{P}$ & $\mathrm{W}$ \\
\hline 1 & $90.80 \pm 0.05$ & $9.20 \pm 0.05$ & $-\mathrm{-}$ \\
2 & $89.04 \pm 0.14$ & $8.87 \pm 0.07$ & $2.09 \pm 0.09$ \\
3 & $90.55 \pm 0.19$ & $6.71 \pm 0.16$ & $2.75 \pm 0.28$ \\
4 & $90.69 \pm 0.16$ & $6.16 \pm 0.13$ & $3.15 \pm 0.15$ \\
5 & $91.11 \pm 0.61$ & $4.25 \pm 0.06$ & $4.64 \pm 0.67$ \\
\hline
\end{tabular}




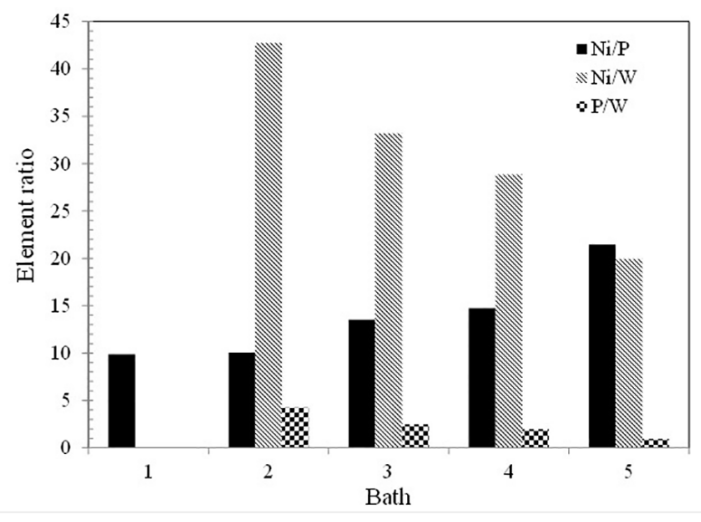

Figure 2. Variation of the $\mathrm{Ni} / \mathrm{P}, \mathrm{Ni} / \mathrm{W}$ and $\mathrm{P} / \mathrm{W}$ ratios for the different coatings as determined from EDS analysis.

Film thickness was assessed by analyzing SEM micrographs of the cross-sections of the deposited films. The SEM micrographs of cross-sections for the different films are shown in Fig. 3 and Fig. 4. The vertical bars displayed in each micrograph were inserted to allow for a visual indication of the deposited layer. The thicknesses were determined at different points along the film. The average thickness obtained for each plating bath is shown in Tab. 3. The deposition time was the same for all the baths. The thickness was relatively homogeneous and continuous along the width of the coating layer independently of the plating bath. The thinnest layer was obtained in bath 5 , suggesting that the highest tungsten concentration of this plating bath reduced the deposition rate. Film thickness can be an important factor affecting the corrosion behavior of plated metals. This influence will be discussed in section 3.5.

Table 3. Film thickness determined from SEM micrographs of cross-sections of films obtained in baths with different tungsten concentrations.

\begin{tabular}{cc}
\hline Bath & Film thickness $(\mathrm{mm})$ \\
\hline 1 & $27.01 \pm 1.77$ \\
2 & $22.46 \pm 1.09$ \\
3 & $30.87 \pm 0.55$ \\
4 & $34.06 \pm 1.14$ \\
5 & $14.60 \pm 1.39$ \\
\hline
\end{tabular}

Additional compositional analysis of the cross-sections of the different coatings was performed using the linescan tool of the EDS software in order to reveal the presence of the main constituents of the coatings across the layer and at the interface with the steel substrate. The results are also shown in Fig. 3 and Fig. 4 at right of the cross-sectional SEM micrographs. The presence of $\mathrm{Ni}$ and $\mathrm{P}$ is promptly seen in the linescans together with small quantities of $\mathrm{Fe}$, independently of the tungsten concentrations. Tungsten signal was detected with small intensities for the coatings obtained in baths 2 to 5 , confirming its incorporation for the specimens treated in these baths. The presence of $\mathrm{Fe}$ can be a result of a small scale interdiffusion between the substrate and the coating. The presence of an interdiffusion layer has been reported for electroless Ni-P coatings ${ }^{27}$ and is frequently associated with annealing treatments above $600^{\circ} \mathrm{C}$. Notwithstanding, short range movement of atoms can take place at lower temperatures from 300 to $600^{\circ} \mathrm{C}^{28}$. However, the formation of an interdiffusion layer is more likely to occur above $600^{\circ} \mathrm{C}^{29}$. We did not detect the presence of an interdiffusion layer, since the relative counts of $\mathrm{Ni}$ and $\mathrm{P}$ sharply decreased from the film to the substrate and that of Fe sharply decreased from the substrate to the film. Nevertheless, Fe iron signal was detected at the coating layer, suggesting that some diffusion could have occurred during deposition and subsequent annealing at $400^{\circ} \mathrm{C}$. In order to confirm this possibility, EDS mapping analyses of untreated samples were also performed to check for the presence of iron in the coating layer even in the as-deposited condition. The results are shown in Fig. 5 for a sample obtained in bath 3 . The results for the other films were very similar and are not presented here. The cross-sectional SEM micrograph of the coating layer is shown in Fig. 5a. EDS mapping analyses for phosphorus, iron, nickel and tungsten are shown in Figs. 5b, 5c, 5d and 5e, respectively. As seen in Fig. 5c the iron signal is stronger at the substrate but it is also detected at the coating layer. Nickel, phosphorus and tungsten are mainly present at the coating layer, as expected. Diffusion is enhanced during heat treatment of the electroless nickel layer. Since iron was detected in the coating layer even in the as-deposited condition it is likely that it participated in the reaction process during film formation and not as a result of interdiffusion during heat treatment.

Surface morphology was considerably affected by the tungsten content. Figures 6 and 7 show SEM micrographs of the as-deposited coatings obtained in baths with different tungsten concentrations. For the conventional Ni-P film obtained in bath 1 (Fig. 6a) the morphology is predominantly smooth with the presence of some small cavities which is a common feature of electroless nickel deposits ${ }^{30}$. Fort the coatings produced in bath 2 (Fig. 6b) small nodules were formed which were not observed in the conventional Ni-P film (Fig. 6a). In this regard, baths 3 and 4 (Figs. 7a and $7 \mathrm{~b}$, respectively) produced coatings with a similar nodular morphology. The nodules size seemed to increase for the coatings obtained in bath 4 . The formation of nodular structures in films obtained by electroless deposition depends on the nucleation and growth rate of the deposit. The nucleation rate is a function of bath composition, $\mathrm{pH}$, temperature and impurities, whereas the growth rate depends on the concentrations of the species in the plating bath ${ }^{31-33}$. Nodular structure is favored by a high nucleation rate during deposition ${ }^{22}$. When the tungsten concentration was further increased (bath 5), the nodular morphology was remarkably 

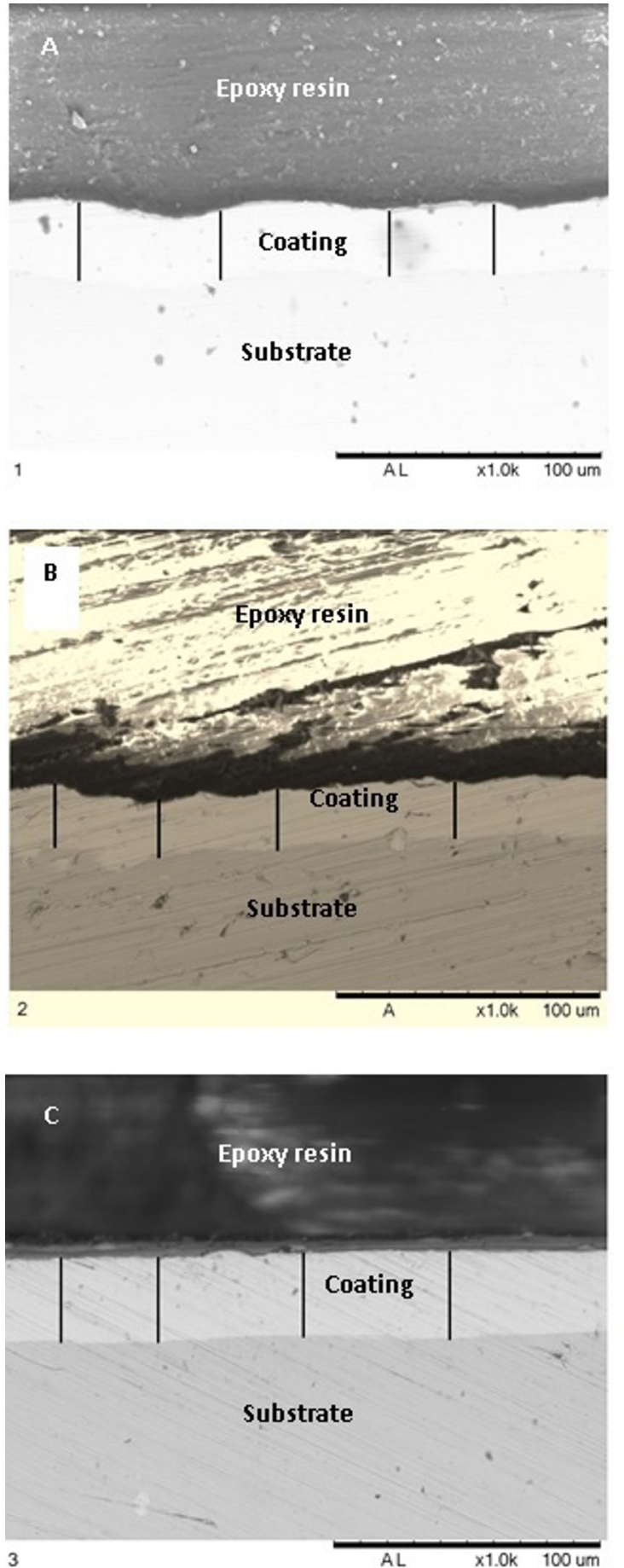
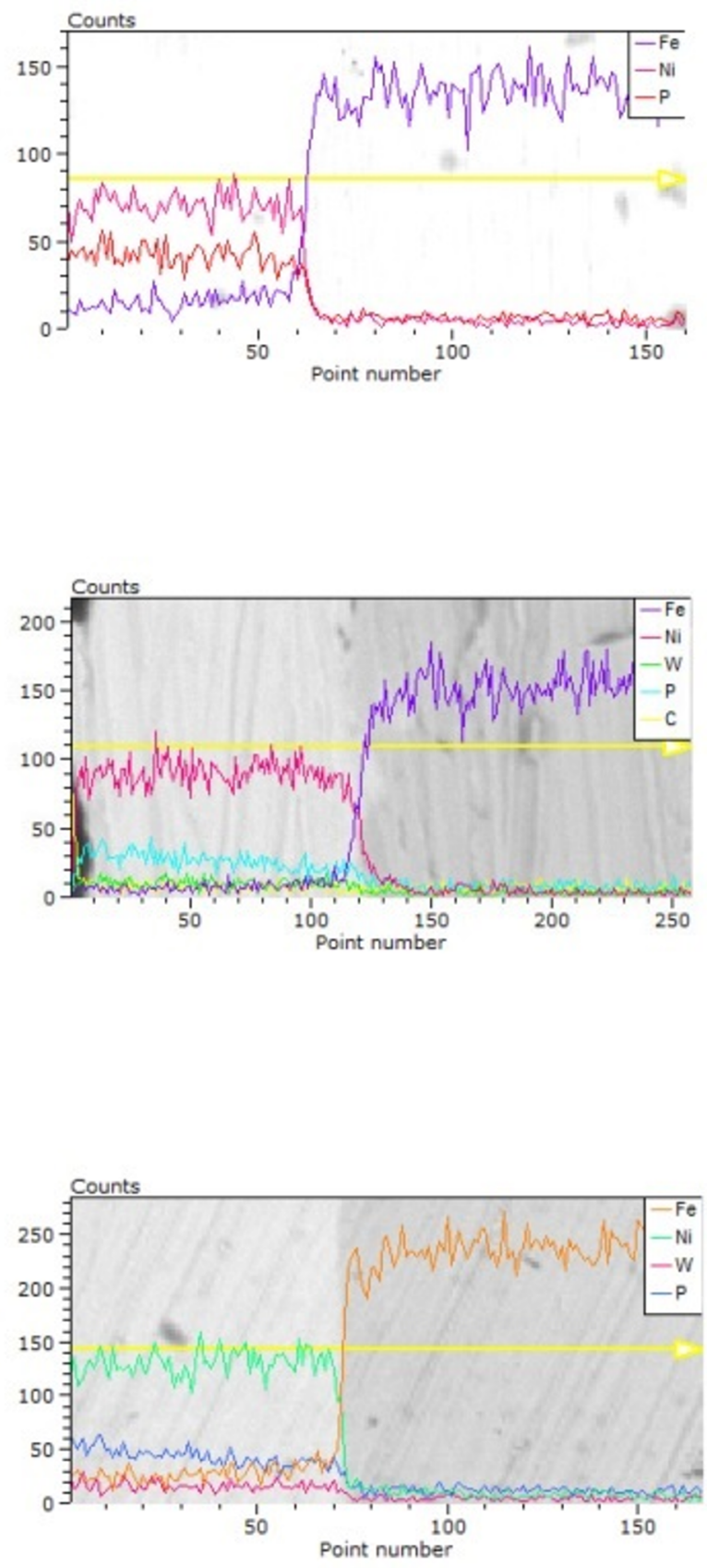

Figure 3. SEM micrographs of cross-sections of the coatings obtained in baths with different tungsten concentrations: a) bath 1; b) bath 2; c) bath 3. The corresponding EDS linescans are shown at right.

enhanced as shown in Fig. 7c. Small pores are also spread over the surface. The morphological features of a protective coating can strongly affect its corrosion resistance. Next section deals with this subject, aiming at identifying the correlation between tungsten concentration and the electrochemical behavior of the Ni-W-P films obtained in this work.

\subsection{Nanoindentation tests}

Figure 8 presents typical nanoindentation load - penetration depth curves for the coatings obtained in baths with different tungsten concentrations. Hardness (H), Young's modulus (E) and the $\mathrm{H} / \mathrm{E}$ ratio were determined from these curves and the values are reported in Tables 4 and 5 for the as-deposited 

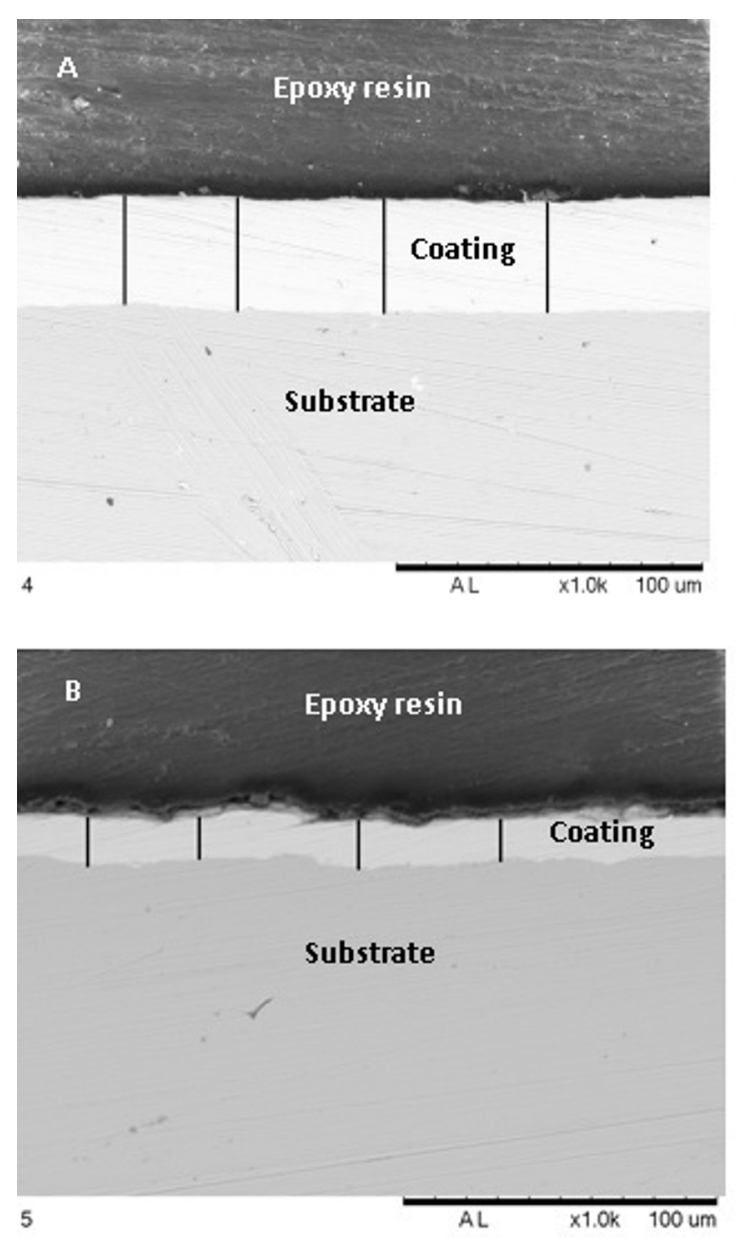
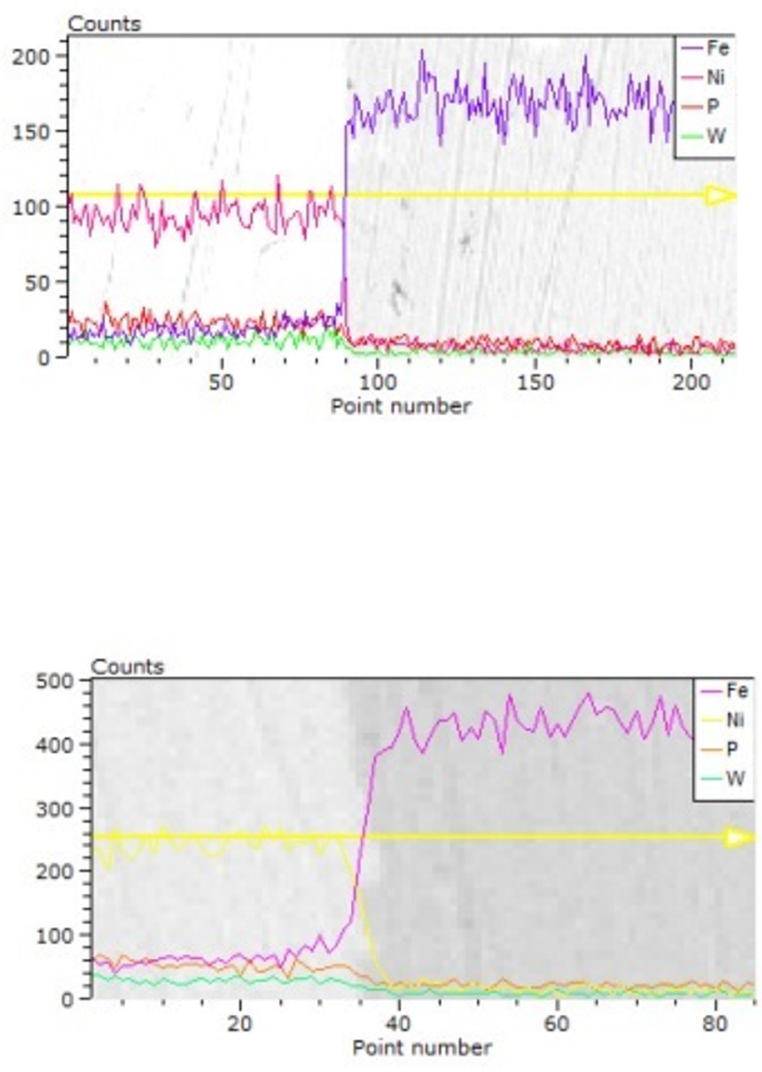

Figure 4. SEM micrographs of cross-sections of the coatings obtained in baths: d) 4 and e) 5. The corresponding EDS linescans are shown at right.

and annealed films, respectively. The $\mathrm{H} / \mathrm{E}$ ratio is related to the surface wear resistance, being employed as an indirect indication of this property for thin films ${ }^{34}$.

It is seen from Fig. 8 that the maximum penetration depth and residual depth after unloading decreased for the annealed coatings when compared to the as-deposited state. This effect would reflect the precipitation of $\mathrm{Ni}_{3} \mathrm{P}$ crystallites upon annealing, as indicated by the XRD results (Fig. 1), independently of the tungsten concentration. This behavior indicates that hardness increased upon annealing for all the coatings as shown in Tables 4 and 5. The Young's modulus was also affected by the heat treatment, increasing after annealing. This effect was reported by other authors and is due to the precipitation of $\mathrm{Ni}_{3} \mathrm{P}$ crystallites in the nickel matrix ${ }^{35}$.

Hardness was also dependent on the tungsten concentration in the film. It is seen from Tables 4 and 5 that hardness increased with the tungsten concentration in both the as-deposited and annealed specimens. This solid solution strengthening by tungsten incorporation into Ni-P films has been observed by Li et al. ${ }^{36}$, revealing the importance of controlling the tungsten content of electroless Ni-W-P coatings to achieve optimize their surface properties.
It is interesting to note, yet, that the $\mathrm{H} / \mathrm{E}$ ratio of the Ni-W-P was optimized for the coatings obtained in baths 3 and 4 with respect to the other films. This ratio takes into account the elastic strain to failure of a thin film, being related to its elasticity and toughness and, ultimately, to its wear resistance. In this regard, the results reported here indicate that tungsten effectively improved the surface properties of the Ni-P conventional layer. This effect was more pronounced for the intermediate tungsten contents.

\subsection{Surface roughness and friction characteristics}

The surface topography of the coatings obtained in baths 1 to 5 is presented in Tab. 6 that presents CLSM 3D images of the coatings in the as-deposited and annealed conditions. The corresponding surface roughness of the coatings is shown in Fig. 9. The values are expressed as the Ra parameter that corresponds to the arithmetic average roughness of surface and is widely used to characterize the surface profile of engineering materials ${ }^{37}$. The CLSM 3D views indicate that the surface topography is relatively smooth, except for the coating obtained in bath 1 in the as-deposited condition. 

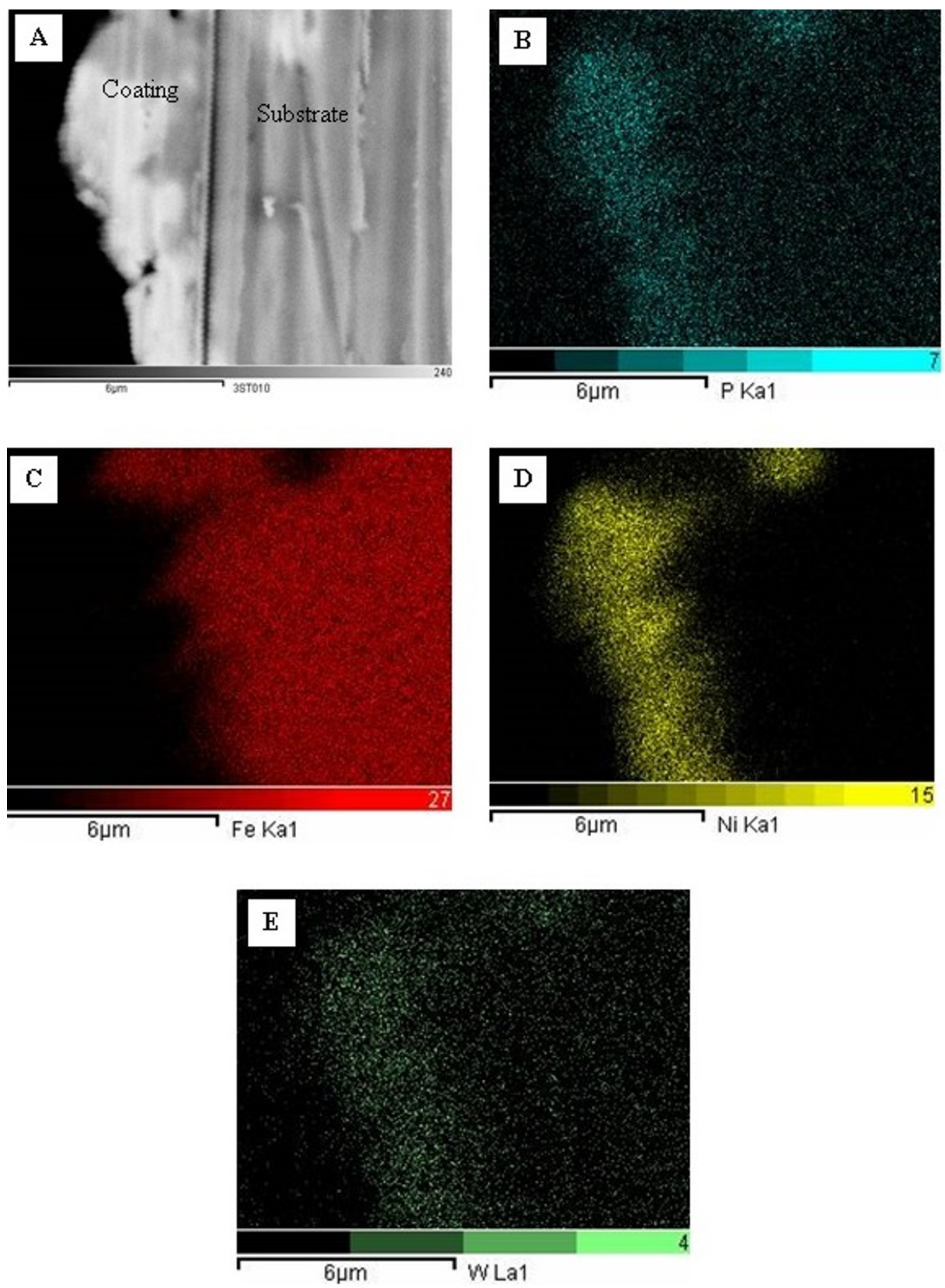

Figure 5. EDS mapping analysis of cross-sections of the coatings obtained in bath 3: a) SEM micrograph; b) P mapping; c) Fe mapping; d) Ni mapping; e) W mapping. 

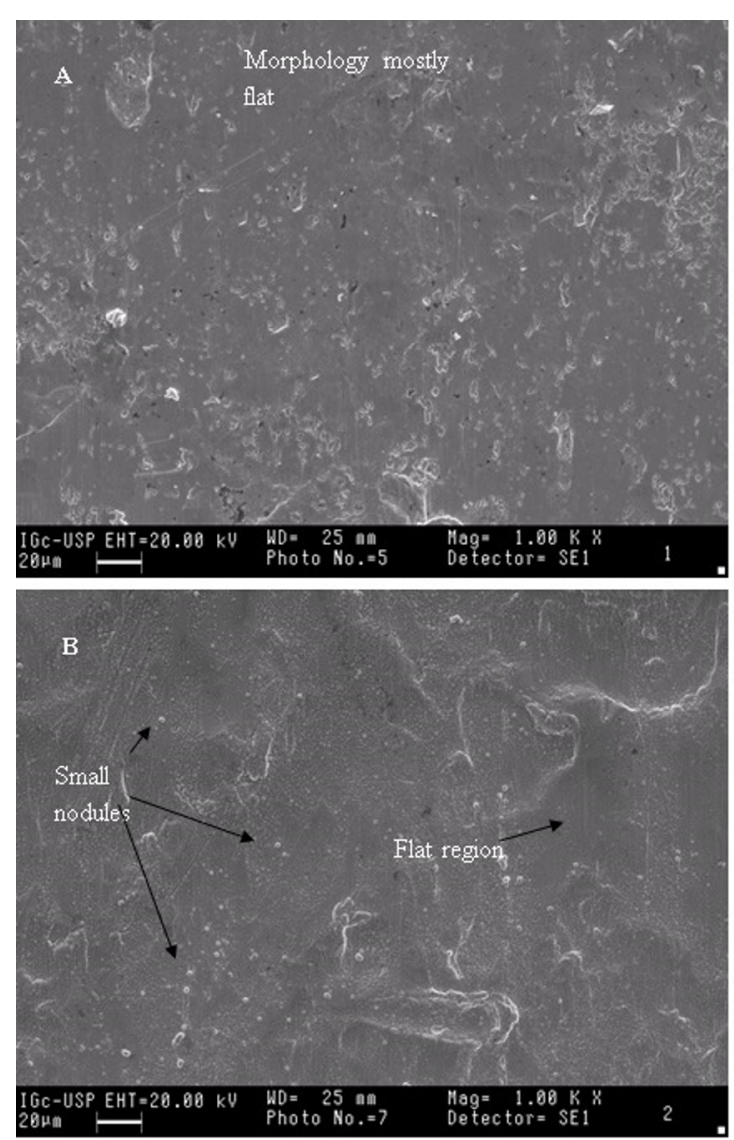

Figure 6. SEM micrographs of the top surfaces of the as-deposited coatings obtained in baths: a) 1 and b) 2 .

There was a trend of decreasing surface roughness after annealing for the coatings obtained in baths 1,2 and 3. For the coatings with higher tungsten concentrations (4 and 5), though, the Ra value in the annealed state was nearly the same as in the as-deposited condition. The surface roughness of electroless nickel coatings can be affected by annealing. Diffusion of nickel atoms upon annealing of Ni-P coatings is reported to decrease the surface roughness. Although this effect should not be disregarded for the coatings obtained in baths 1, 2 and 3, it is not active for the coatings produced in baths 4 and 5. It is possible that an increase in tungsten concentration promotes a reduction of the film roughness by affecting the film morphology. As indicated in the SEM micrographs shown in Figs. $7 \mathrm{~b}$ and $7 \mathrm{c}$ a nodular structure was enhanced for the films obtained in baths 4 and 5 , leading to a smoother surface.

The variation of the friction coefficient with the sliding distance during reciprocating wear tests of coatings obtained in baths 1 to 5 is shown in Fig. 10. The friction coefficient curves at the as-deposited state (Fig. 10a) present higher fluctuations with the sliding distance when compared to the curves obtained for the coatings in the annealed state (Fig. 10b). This effect would be related to the smoother surfaces obtained after annealing being more significant
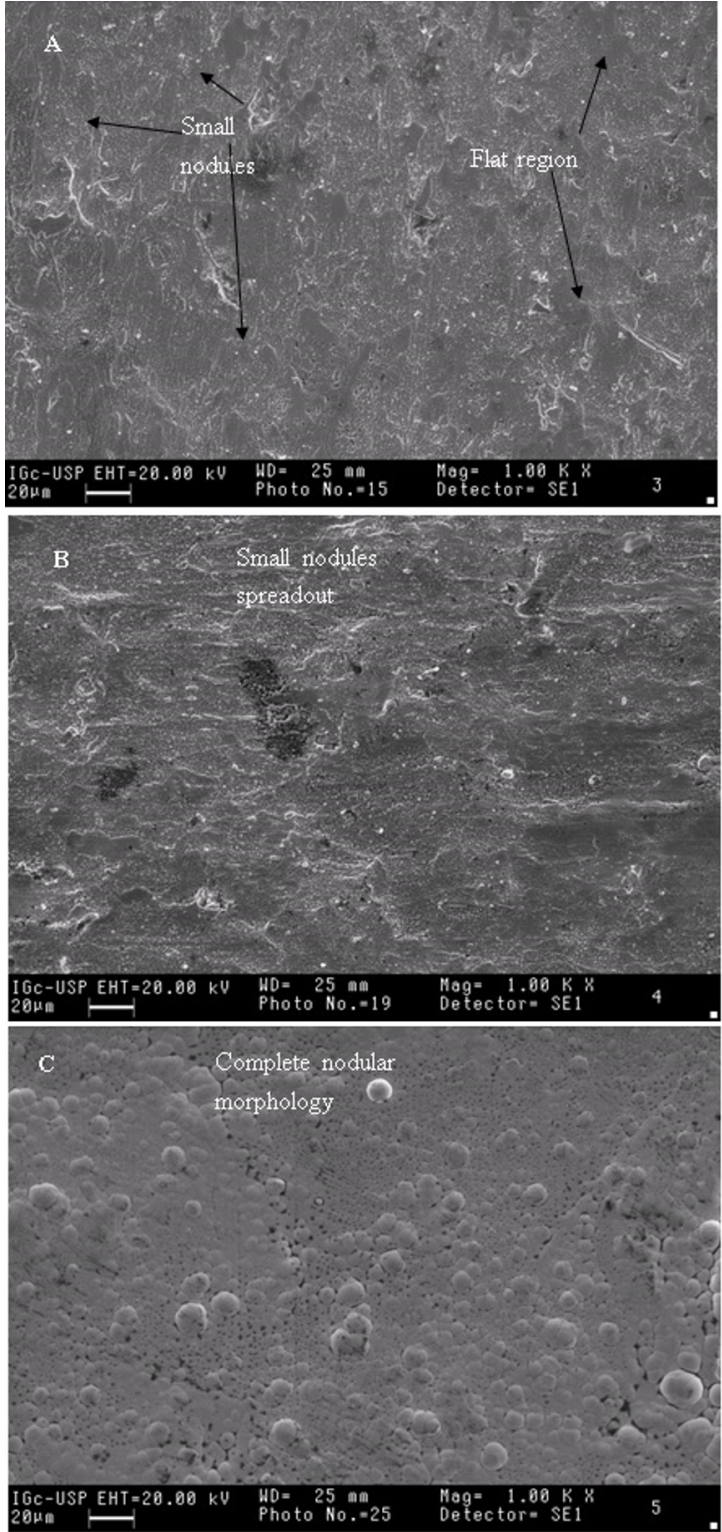

Figure 7. SEM micrographs of the top surfaces of the as-deposited coatings obtained in baths with different tungsten concentrations: a) bath 3 ; b) bath 4 ; c) bath 5 .

for the coatings obtained in baths 1 and 2 which are the least smooth coatings in the as-deposited condition. The smoothest surfaces yielded the lowest values of the friction coefficient either in the as-deposited. Similar findings have been reported by other authors ${ }^{38}$.

The influence of Ra for the annealed specimens is not very clear. It is seen that the friction coefficient for the coating obtained in bath 3 is lower than that of the coating obtained in bath 1 in the annealed state (Fig. 10b). Notwithstanding, its value of Ra is very similar to that of the specimen plated in bath 1 . Moreover, the film produced in bath 5 is rougher than those obtained in baths 3 and 1 (Fig. 9) but its friction coefficient is lower in the annealed state (Fig. 10b). It 

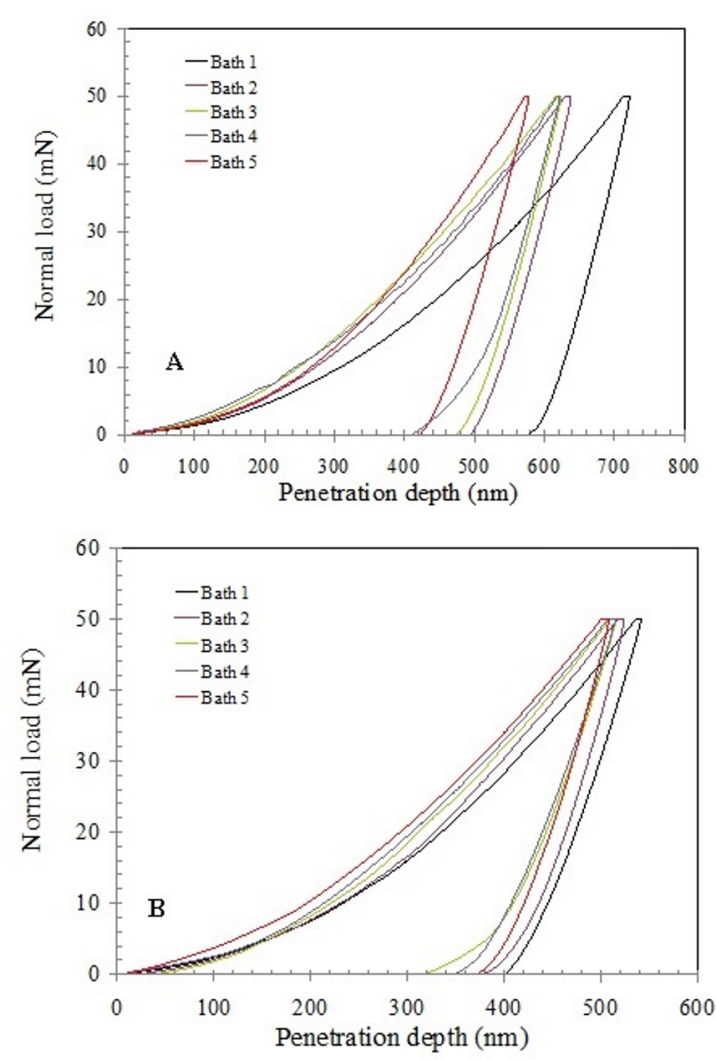

Figure 8. Load versus penetration depth curves for the coatings obtained in baths with different tungsten concentrations: a) Asdeposited; b) annealed at $400{ }^{\circ} \mathrm{C}$ for $1 \mathrm{~h}$.

Table 4. Hardness (H), Young's modulus (E) and H/E ratio of the coatings produced in baths 1 to 5 in the as-deposited condition.

\begin{tabular}{cccc}
\hline Bath & $\mathrm{H}(\mathrm{GPa})$ & $\mathrm{E}(\mathrm{GPa})$ & $\mathrm{H} / \mathrm{E}$ \\
\hline 1 & 5.64 & 151.0 & 0.038 \\
2 & 7.27 & 160.1 & 0.045 \\
3 & 7.78 & 174.5 & 0.045 \\
4 & 8.55 & 168.1 & 0.051 \\
5 & 8.97 & 166.8 & 0.054 \\
\hline
\end{tabular}

Table 5. Hardness (H), Young's modulus (E) and H/E ratio of the coatings produced in baths 1 to 5 after annealing for at $400{ }^{\circ} \mathrm{C} 1 \mathrm{~h}$.

\begin{tabular}{cccc}
\hline Bath & $\mathrm{H}(\mathrm{GPa})$ & $\mathrm{E}(\mathrm{GPa})$ & $\mathrm{H} / \mathrm{E}$ \\
\hline 1 & 10.2 & 217.9 & 0.047 \\
2 & 10.6 & 263.1 & 0.040 \\
3 & 11.7 & 214.0 & 0.055 \\
4 & 12.0 & 241.9 & 0.050 \\
5 & 11.0 & 235.8 & 0.047 \\
\hline
\end{tabular}

seems, therefore, that other aspects should affect the friction properties of the Ni-W-P films produced in the present work.

In addition to the surface roughness, the mechanical properties of coatings such as hardness and Young's modulus are often related to the friction characteristics. The friction coefficient is lower for hard surfaces when compared to more ductile ones ${ }^{35}$. This effect would manifest upon annealing due to the precipitation of $\mathrm{Ni}_{3} \mathrm{P}$ phase as confirmed by the XRD patterns shown in Fig. 1. One additional aspect related to the friction coefficient is surface morphology. A nodular structure, forming cauliflower aspect is often associated with a reduced friction coefficient, as reported by Duari et al. ${ }^{39}$. In this respect, the lowest friction coefficient of the coating obtained in bath 5 would reflect the influence of hardness, roughness and surface morphology.

\subsection{Corrosion behavior}

Potentiodynamic polarization curves of the as-deposited coatings obtained in baths with different tungsten concentrations are shown in Fig. 11. The electrolyte was 3.5 wt. $\% \mathrm{NaCl}$ solution at room temperature. Corrosion parameters obtained from these curves are displayed in Tab. 7.

The corrosion potential $\left(\mathrm{E}_{\text {corr }}\right)$ of the coated specimens was shifted to nobler values in comparison with the bare substrate, indicating better stability in the electrolyte for all plating conditions with respect to the uncoated steel. In the same way, the corrosion current density $\left(\mathrm{i}_{\text {corr }}\right)$ decreased for the plated specimens. Electroless nickel plating has been reported to reduce the corrosion rate of metallic substrates due to a barrier effect. Literature reports indicate that nickel is preferentially dissolved at the open circuit potential, thus leading to phosphorus enrichment on the surface of the coated substrate ${ }^{40}$. By reacting with water, hypophosphite ions are formed according to equation (1). The adsorbed hypophosphite layer has a blocking action on the coated surface, preventing nickel hydration due to a limited water supply which is reported to be the initial stage for the formation of soluble $\mathrm{Ni}^{2+}$ or a nickel passive layer ${ }^{41,42}$.

$$
\mathrm{P}+2 \mathrm{H}_{2} \mathrm{O} \leftrightarrow \mathrm{H}_{2} \mathrm{PO}_{2^{-}}+\mathrm{e}^{-}
$$

The effect of tungsten addition on the corrosion resistance of the as-plated films can be promptly perceived by the data shown in Tab. 7. No significant beneficial effect of tungsten incorporation into the Ni-P can be detected in comparison with the conventional Ni-P films obtained in bath 1. The decreased phosphorus content in the as-plated films after tungsten incorporation could have a negative effect on the formation of a protective hypophosphite layer on the coated surfaces. A similar trend has been also reported by Balaraju et al. ${ }^{17}$. However, the deposit obtained in bath 5 , that presents the lowest phosphorus concentration according to the EDS data (Tab. 2), shows the highest corrosion resistance as denoted by its low $i_{\text {corr }}$ value. This behavior seems to be in contrast with the surface morphology shown in Fig. 7c in which it is possible to see the presence of several small pores spread over the film surface. The presence of such defective features would facilitate the penetration of electrolyte through the coating, thus leading to substrate corrosion. Nevertheless, 
Table 6. 3D CLSM images of coatings in the as-deposited and annealed conditions.

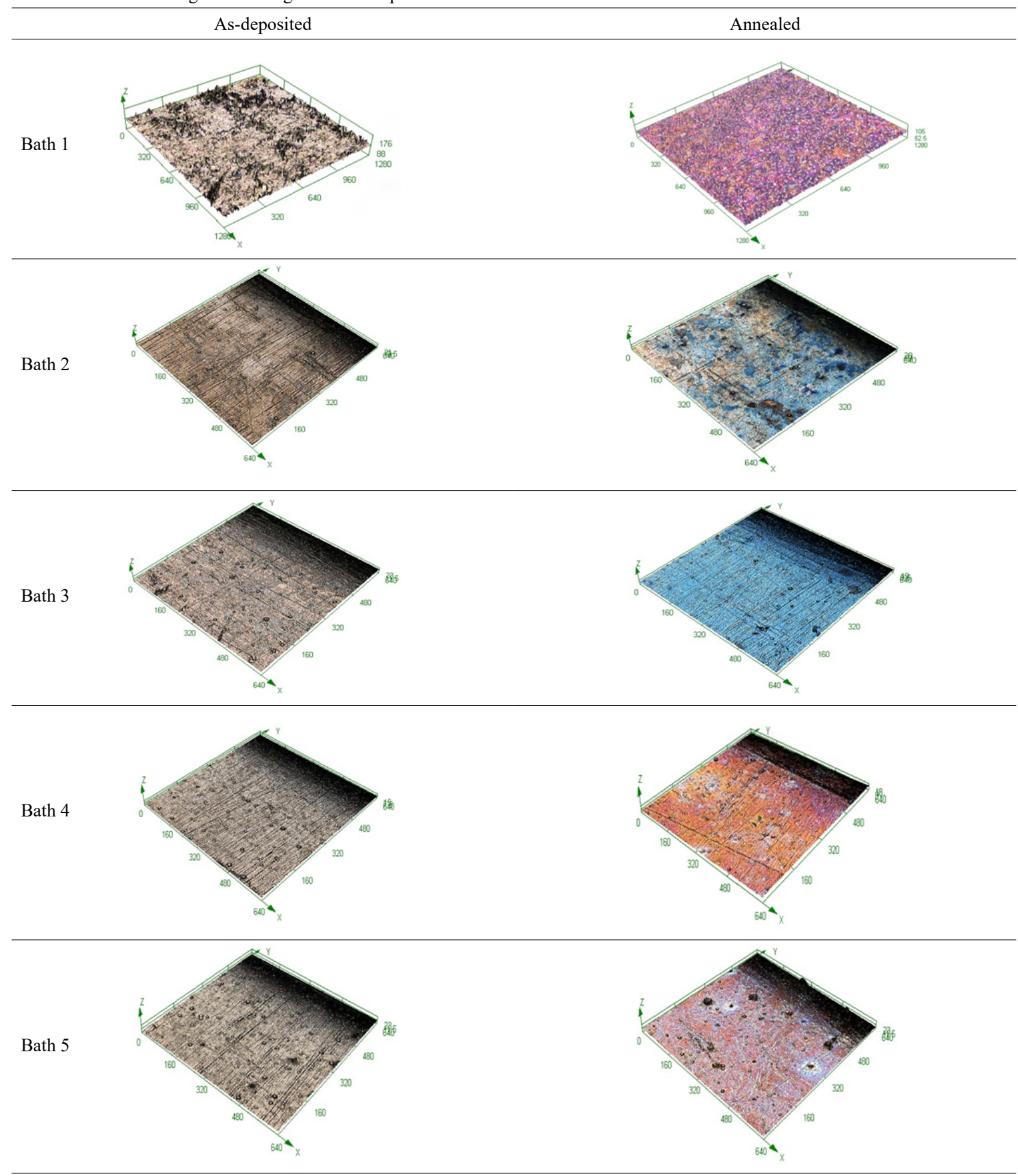

as shown in the cross-section SEM micrograph of Fig. 4b, this deposit is dense and compact. Hence, the small pores in its top surface did not reach the substrate. Hence, the corrosion resistance may not be hampered in this situation, as observed by other authors ${ }^{22}$.

Potentiodynamic polarization tests of the films obtained in baths 1 to 5 after annealing at $400^{\circ} \mathrm{C}$ were conducted according to the same conditions used for the as-plated films. The polarization curves are shown in Fig. 12. Corrosion parameters obtained from these curves are displayed in Tab. 8. The results reveal a trend of gradual increase of corrosion potential with the tungsten content in the film as well as a progressive decrease of the corrosion current densities.

Tungsten incorporation can enhance the corrosion properties of electroless Ni-P after annealing at temperatures ranging from $400^{\circ} \mathrm{C}$ to $600^{\circ} \mathrm{C}^{17}$. This effect would manifest due to diffusion of the passivating element tungsten, thereby increasing the protective character of the deposited layer, forming a more stable passive film. The excellent performance of the film obtained in bath 5 which is the most tungsten- 


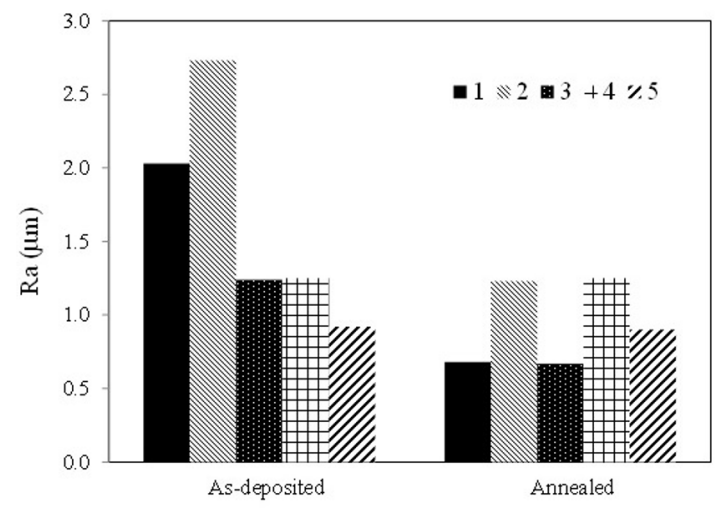

Figure 9. Surface roughness of the coatings produced in baths 1 to 5 in the as-deposited and annealed conditions.
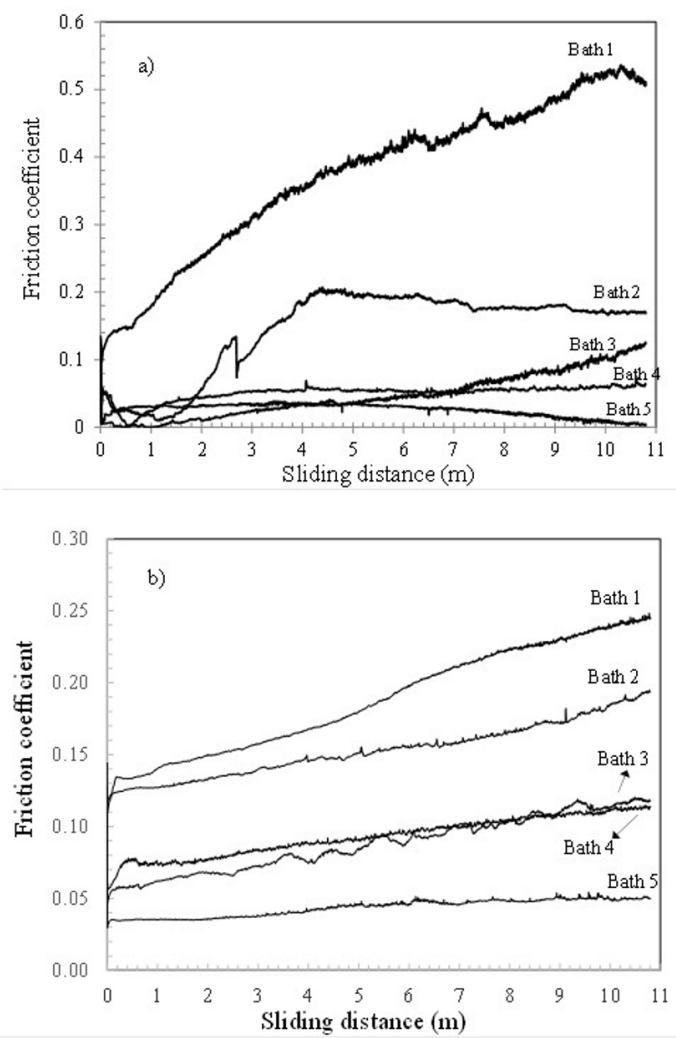

Figure 10. Friction coefficient versus sliding distance during reciprocating wear tests for the coatings obtained in baths with different tungsten concentrations: a) As-deposited; b) annealed at $400^{\circ} \mathrm{C}$ for $1 \mathrm{~h}$.

enriched layer would be a consequence of this effect. It is also interesting to note that, in spite of the relatively small thickness of the coating obtained in bath 5 in comparison to the other ones (see Tab. 3), its corrosion resistance was not reduced. In this respect, the superior concentration of the passivating element tungsten seem to control the electrochemical response of the Ni-W-P coatings, being the coating thickness of limited influence under the conditions tested in the present work.

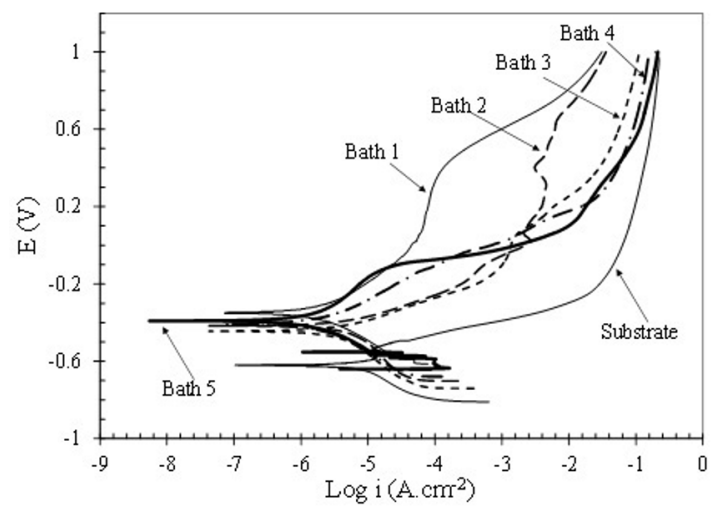

Figure 11. Potentiodynamic polarization curves of the as-deposited coatings obtained in baths with different tungsten concentrations.

Table 7. Corrosion potentials $\left(\mathrm{E}_{\text {corr }}\right)$ and corrosion current densities $\left(\mathrm{i}_{\text {corr }}\right)$ obtained from the polarization curves shown in Fig. 11

\begin{tabular}{ccc}
\hline & $\mathrm{E}_{\text {corr }}(\mathrm{mV})$ & $\mathrm{i}_{\text {corr }}\left(\mathrm{mA}^{\mathrm{c}} \mathrm{cm}^{-2}\right)$ \\
\hline Substrate & -621 & 8.71 \\
Bath 1 & -347 & 1.63 \\
Bath 2 & -414 & 5.88 \\
Bath 3 & -445 & 3.72 \\
Bath 4 & -410 & 2.08 \\
Bath 5 & -390 & 1.46 \\
\hline
\end{tabular}

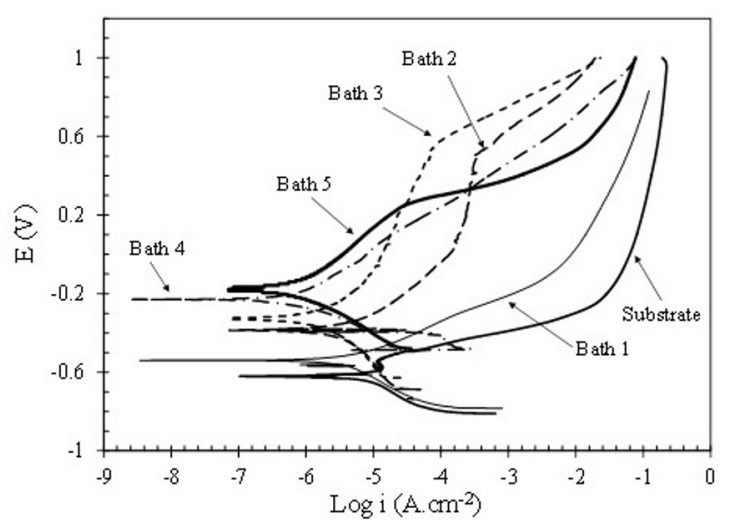

Figure 12. Potentiodynamic polarization curves of the coatings obtained in baths with different tungsten concentrations after annealing at $400^{\circ} \mathrm{C}$ for $1 \mathrm{~h}$.

Table 8. Corrosion potentials $\left(\mathrm{E}_{\text {corr }}\right)$ and corrosion current densities $\left(\mathrm{i}_{\text {corr }}\right)$ obtained from the polarization curves shown in Fig. 12.

\begin{tabular}{ccc}
\hline & $\mathrm{E}_{\text {corr }}(\mathrm{mV})$ & $\mathrm{i}_{\text {corr }}\left(\mu \mathrm{A} \cdot \mathrm{cm}^{-2}\right)$ \\
\hline Substrate & -621 & 8.71 \\
Bath 1 & -540 & 4.17 \\
Bath 2 & -388 & 3.02 \\
Bath 3 & -328 & 1.93 \\
Bath 4 & -228 & 0.79 \\
Bath 5 & -177 & 0.53 \\
\hline
\end{tabular}




\section{Conclusions}

Electroless Ni-W-P films were produced in baths with different tungsten concentrations. XRD patterns indicated that $\mathrm{Ni}$ and $\mathrm{Ni}_{3} \mathrm{P}$ crystallites were present after annealing at $400^{\circ} \mathrm{C}$, independently of the tungsten concentration. Film morphology was affected by tungsten incorporation. The highest tungsten content produced a smooth and nodular morphology. The phosphorus content was progressively reduced as the tungsten content increased in the film. Coatings hardness increased after annealing and scaled with tungsten concentration. The surface roughness was affected by the tungsten content, decreasing as the surface morphology became more nodular. The lowest friction coefficient was associated with the hardest and smoothest surfaces which, in turn, were obtained for the coatings with high tungsten concentrations. The corrosion behavior, in turn, was little affected by tungsten incorporation in the as-plated state whereas the surface stability and corrosion resistance increased for higher tungsten contents in the film after annealing at $400^{\circ} \mathrm{C}$.

\section{Acknowledgments}

The authors are thankful to the Brazilian agencies FINEP (Proc. 04.12.0045.00) and CNPq (Proc. 550054/2013-8) for the financial support to this work.

\section{References}

1. Taheri R, Oguocha INA, Yannacopoulos S. The tribological characteristics of electroless NiP coatings. Wear. 2001;249(56):389-396.

2. Chen XM, Li GY, Lian JS. Deposition of electroless Ni-P/NiW-P duplex coatings on AZ91D magnesium alloy. Transactions of the Nonferrous Metals Society of China. 2008;18(Suppl 1):s323-s328.

3. Shen YF, Xue WY, Liu ZY, Zuo L. Nanoscratching deformation and fracture toughness of electroless Ni-P coatings. Surface and Coatings Technology. 2010;205(2):632-640.

4. Li Y, Kumar P, Shi X, Nguyen TA, Xiao Z, Wu J. Electroless Synthesis of Ni-P and Ni-P-Zn Alloy Coatings for Protecting Steel Rebar from Chloride-Induced Corrosion. International Journal of Electrochemical Science. 2012;7:8151-8169.

5. Mainier FB, Fonseca MPC, Tavares SSM, Pardal JM. Quality of Electroless Ni-P (nickel-phosphorus) Coatings Applied in Oil Production Equipment with Salinity. Journal of Materials Science and Chemical Engineering. 2013;1(6):1-8.

6. Chen H, Wang Q, Dong H, Xi L, Lin X, Pan F, et al. Electroless Plating of Ni-P-W Coatings Containing Scattered $\mathrm{Nb}_{2} \mathrm{O}_{5}$ on Sintered NdFeB Substrate. Materials Research. 2015;18(5):10891096.

7. Hu Y, Yang L, Shi C, Tang W. Microstructural evolution and phase transformation kinetics of pulse-electroplated Ni-Cu-P alloy film during annealing. Materials Chemistry and Physics. 2013;141(2-3):944-950.
8. Narayanan TSNS, Selvakumar S, Stephen A. Electroless NiCo-P ternary alloy deposits: preparation and characteristics. Surface and Coatings Technology. 2003;172(2-3):298-307.

9. Zhang WX, Jiang ZH, Li GY, Jiang Q, Lian JS. Electroless $\mathrm{Ni}-\mathrm{Sn}-\mathrm{P}$ coating on AZ91D magnesium alloy and its corrosion resistance. Surface and Coatings Technology. 2008;202(12):25702576.

10. Balaraju JN, Chembath M. Electroless ternary NiCeP coatings: Preparation and characterisation. Applied Surface Science. 2012;258(24):9692-9700.

11. Ashassi-Sorkhabi H, Aminikia H, Bagheri R. Electroless Deposition of Ni-Cu-P Coatings Containing Nano- $\mathrm{Al}_{2} \mathrm{O}_{3}$ Particles and Study of its Corrosion Protective Behavior in $0.5 \mathrm{M} \mathrm{H}_{2} \mathrm{SO}_{4}$. International Journal of Corrosion. 2014;2014:391502.

12. Balaraju JN, Rajam KS. Electroless deposition of Ni-Cu-P, NiW-P and Ni-W-Cu-P alloys. Surface and Coatings Technology. 2005;195(2-3):154-161.

13. Palaniappa M, Seshadri SK. Friction and wear behavior of electroless Ni-P and Ni-P-W alloy coatings. Wear. 2008;265(56):735-740.

14. Palaniappa M, Seshadri SK. Structural and phase transformation behaviour of electroless Ni-P and Ni-P-W. Materials Science and Engineering: A. 2007;460-461:638-644.

15. Gao Y, Zhang ZJ, Zhu M, Luo CP. Corrosion resistance of electrolessly deposited Ni-P and Ni-P-W alloys with various structures. Materials Science and Engineering: A. 2004;381(12):98-103.

16. He FJ, Fang YZ, Jin SJ. The study of corrosion-wear mechanism of Ni-P-W alloy. Wear. 2014;311(1-2):14-20.

17. Balaraju JN, Selvi VE, Grips VKW, Rajam KS. Electrochemical studies on electroless ternary and quaternary Ni-P based alloys. Electrochimica Acta. 2006;52(3):1064-1074.

18. Tien SK, Duh JG. Thermal reliability of electroless Ni-P-W coating during the aging treatment. Thin Solid Films. 2004;469470:268-273.

19. Balaraju JN, Jahan SM, Rajam KS. Studies on autocatalytic deposition of ternary Ni-W-P alloys using nickel sulphamate bath. Surface and Coatings Technology. 2006;201(3-4):507512.

20. Du N, Pritzker M. Investigation of electroless plating of Ni-P-W alloy films. Journal of Applied Electrochemistry. 2003;33(11):1001-1009.

21. Touhami ME, Chassaing E, Cherkaoui M. Kinetics of the autocatalytic deposition of Ni-P alloys in ammoniacal solutions. Electrochimica Acta. 1998;43(12-13):1721-1728.

22. Balaraju JN, Kalavati, Rajam KS. Surface morphology and structure of electroless ternary NiWP deposits with various W and P contents. Journal of Alloys and Compounds. 2009;486(12):468-473.

23. Szczygiel B, Turkiewicz A, Serafinczuk J. Surface morphology and structure of Ni-P, Ni-P-ZrO2, Ni-W-P, Ni-W-P-ZrO2 coatings deposited by electroless method. Surface and Coatings Technology. 2008;202(9):1904-1910. 
24. Liu H, Viejo F, Guo RX, Glenday S, Liu Z. Microstructure and corrosion performance of laser-annealed electroless Ni-P-W coatings. Surface and Coatings Technology. 2010;204(910):1549-1555.

25. Liu H, Guo RX, Zong Y, He BQ, Liu Z. Comparative study of microstructure and corrosion resistance of electroless Ni-W-P coatings treated by laser and furnace-annealing. Transactions of the Nonferrous Metals Society of China. 2010;20(6):10241031.

26. Arai S, Sato T, Endo M. Fabrication of various electroless Ni-P alloy/multiwalled carbon nanotube composite films on an acrylonitrile butadiene styrene resin. Surface and Coatings Technology. 2011;205(10):3175-3181.

27. Rabizadeh T, Allahkaram SR, Zarebidaki A. An investigation on effects of heat treatment on corrosion properties of Ni-P electroless nano-coatings. Materials \& Design. 2010;31(7):31743179 .

28. Sribalaji M, Arunkumar P, Babu KS, Keshri AK. Crystallization mechanism and corrosion property of electroless nickel phosphorus coating during intermediate temperature oxidation. Applied Surface Science. 2015;355:112-120.

29. Eraslan S, Ürgen M. Oxidation behavior of electroless Ni-P, Ni-B and Ni-W-B coatings deposited on steel substrates. Surface and Coatings Technology. 2015;265:46-52.

30. Balaraju JN, Rajam KS. Electroless Deposition and Characterization of High Phosphorus Ni-P-Si $\mathrm{N}_{4}$ Composite Coatings. International Journal of Electrochemical Science. 2007;2:747-761.

31. Jagatheeshwaran MS, Elayaperumal A, Arulvel S. The role of calcinated sea shell particles on friction-wear behavior of electroless NiP coating: Fabrication and characterization. Surface and Coatings Technology. 2016;304:492-501.

32. Hadipour A, Monirvaghefi SM, Bahrololoom ME. Electroless deposition of graded Ni-P coating. Surface Engineering. 2015;31(6):399-405.

33. Roy S, Sahoo P. An Experimental Approach for Optimizing Coating Parameters of Electroless Ni-P-Cu Coating Using
Artificial Bee Colony Algorithm. International Scholarly Research Notices. 2014;2014:976869.

34. Leyland A, Matthews A. On the significance of the $H / E$ ratio in wear control: a nanocomposite coating approach to optimised tribological behavior. Wear. 2000;246(1-2):1-11.

35. Sribalaji M, Rahman OSA, Laha T, Keshri AK. Nanoindentation and nanoscratch behavior of electroless deposited nickel-phosphorus coating. Materials Chemistry and Physics. 2016;177:220-228.

36. Li J, Wang D, Cai H, Wang A, Zhang J. Competitive deposition of electroless Ni-W-P coatings on mild steel via a dual-complexant plating bath composed of sodium citrate and lactic acid. Surface and Coatings Technology. 2015;279:9-15.

37. Oliveira AC, Oliveira MCL, Ríos CT, Antunes RA. The effect of mechanical polishing and finishing on the corrosion resistance of AISI 304 stainless steel. Corrosion Engineering, Science and Technology. 2016;51(6):416-428.

38. Parthasarathi NL, Borah U, Albert SK. Correlation between coefficient of friction and surface roughness in dry sliding wear of AISI $316 \mathrm{~L}(\mathrm{~N})$ stainless steel at elevated temperatures. Computer Modelling and New Technologies. 2013;17(1):51-63.

39. Duari S, Mukhopadhyay A, Barman TK, Sahoo P. Study of wear and friction of chemically deposited Ni-P-W coating under dry and lubricated condition. Surface and Interfaces. 2017;6:177-189.

40. Elsener B, Crobu M, Scorciapino MA, Rossi A. Electroless deposited Ni-P alloys: corrosion resistance mechanism. Journal of Applied Electrochemistry. 2008;38:1053-1060.

41. Balaraju JN, Narayanan TSNS, Seshadri S. Evaluation of the corrosion resistance of electroless Ni-P and Ni-P composite coating by electrochemical impedance spectroscopy. Journal of Solid State Electrochemistry. 2001;5(5):334-338.

42. Rabizadeh T, Allahkaram SR. Corrosion resistance enhancement of Ni-P electroless coatings by incorporation of nano- $\mathrm{SiO}_{2}$ particles. Materials \& Design. 2011;32(1):133-138. 